\title{
Serotonin Syndrome after Clomipramine Overdose in a Child
}

\author{
Meltem Çobanoğulları Direk ${ }^{1}$, Veli Yıldırım ${ }^{2}$, Serkan Güneş ${ }^{2}$, Gülçin Bozlư ${ }^{3}$, Çetin Okuyaz ${ }^{1}$ \\ ${ }^{1}$ Division of Pediatric Neurology, Department of Pediatrics, ${ }^{2}$ Department of Child and Adolescent Psychiatry, ${ }^{3}$ Department of Pediatrics, \\ University of Mersin School of Medicine, Mersin, Turkey
}

\begin{abstract}
Serotonin syndrome (SS) is a potentially life-threatening condition associated with increased serotonergic activity in central nervous system and may occur during the use of serotonergic drugs. Although increasing frequency of serotonergic drug use in children, pediatricians, emergency medicine and pediatric intensive care specialists have not enough knowledge and experience about SS that is a potentially life-threatening condition. A 12-year-old girl patient was admitted to our emergency room with the history of involuntary contractions on her extremities and alteration of consciousness. Her physical examination showed agitation, hyperthermia, dilated pupils, tremor, increased deep tendon reflexes, positive spontaneous clonus, agitation, flushed skin and diaphoresis, excessive perspiration, and continuous horizontal ocular movements. The patient diagnosed as SS by clinical history, physical and laboratory findings. In this paper, we will discuss SS occurred in a 12-year-old girl after concurrent clomipramine and risperidone use.
\end{abstract}

KEY WORDS: Child; Clomipramine; Serotonin syndrome; Risperidone; Early diagnosis.

\section{INTRODUCTION}

Serotonin syndrome (SS) is a potentially life-threatening condition associated with increased serotonergic activity in central nervous system. SS may occur during the use of serotonergic drugs. Clinical findings include mental state alterations, autonomic hyperactivity and neuromuscular excitability. ${ }^{1)}$ Neuroleptic malignant syndrome, anticholinergic toxicity, malignant hyperthermia, sympathomimetic agent intoxications, central nervous system infections should be considered in differential diagnosis. ${ }^{1,2)}$ Although there are limited numbers of pediatric case reports concerning $\mathrm{SS},{ }^{3-9)}$ making the diagnosis of SS is more difficult in children. In this paper, we will discuss SS occurred in a 12-year-old girl after concurrent clomipramine and risperidone use.

\section{CASE}

A 12-year-old girl was admitted to emergency room

Received: October 27, 2015 / Revised: December 24, 2015

Accepted: January 19, 2016

Address for correspondence: Meltem Çobanoğulları Direk, MD Division of Pediatric Neurology, Department of Paediatrics,

University of Mersin Faculty of Medicine, 34, Cadde, Ciftlikkoy Kampusu 33343 Mersin, Turkey

Tel: +90-5066724367, Fax: +90-324-241-0092

E-mail:m It m82@hotmail.com with the history of involuntary contractions on her extremities and alteration of consciousness. The diagnosis of epilepsy and status epilepticus was made based on her clinical history at onset. The case was hospitalized to pediatric intensive care unit. Heart rate was 140 pulses/minute, her body temperature was $39.5^{\circ} \mathrm{C}$, oxygen saturation was $99 \%$ and blood pressure was $120 / 60 \mathrm{mmHg}$. Her physical examination showed agitation, hyperthermia, dilated pupils, tremor, increased deep tendon reflexes, positive spontaneous clonus, agitation, flushed skin and diaphoresis, excessive perspiration, and continuous horizontal ocular movements. There were no meningeal irritation signs. We suspect the diagnosis of epilepsy and status epilepticus because of incompatible physical signs and symptoms. Detailed clinical history was retaken and physical examination was repeated. Repeated examination showed that nail biting and clues of self-injury behavior. We learned that she has been living with her stepmother and irregularly receiving risperidone for a week prescribed by psychiatry clinic. She had behavioral problems such as stealing money, lying, and escaping from home and school. She had taken nine pills of $75 \mathrm{mg}$ clomipramine tablets for suicidal attempt, which were belonging to her stepmother, in one day. Her abnormal blood chemistry test results were high creatinine kinase and myoglobin levels (creatinine kinase 2,823 U/L [0-145 U/L];

(C) This is an Open-Access article distributed under the terms of the Creative Commons Attribution Non-Commercial License (http://creativecommons.org/licenses/by-nc/4.0) which permits unrestricted non-commercial use, distribution, and reproduction in any medium, provided the original work is properly cited. 
myoglobin $112 \mathrm{ng} / \mathrm{ml}$ [0-7 ng/ml]). Urea, creatinine, $\mathrm{Na}$, $\mathrm{K}$, aspartate transaminase, alanine transaminase, complete blood count, prothrombin time, activated partial thromboplastin time, electroencephalography and brain computed tomography results were normal. The patient has diagnosed as SS. Clomipramine was discontinued, oral diazepam and intravenous hydration was started. Clinical symptoms of the patient disappeared in 24 hours. Two days later, creatinine kinase level regressed to 755 $\mathrm{U} / \mathrm{L}$ and myoglobin level regressed to $15 \mathrm{ng} / \mathrm{ml}$. The patient was consulted to child and adolescent psychiatry clinic as she had suicidal attempt and thoughts of self-injury. The patient's physical examination and laboratory test results returned to the normal ranges four days later and she was discharged from the hospital under the supervision of child and adolescent psychiatry clinic.

\section{DISCUSSION}

Serotonin is one of the most important neurotransmitters affecting mental health. ${ }^{10)} \mathrm{SS}$ is result from serotonergic overstimulation of serotonin receptors. The frequency of serotonergic drug use in pediatric age group is increasing. Serotonergic drugs may use in treatment of many pediatric, psychiatric and neurologic conditions such as migraine, depression, anxiety disorder and obsessive-compulsive disorders. Serotonin is a neurotransmitter produced by presynaptic neurons. There are central and peripheral serotonin receptors. Central serotonin receptors are involved in behavior, mood, sleep-wakefulness cycles, muscular tone and thermoregulation; on the other hand peripheral receptors are involved in gastrointestinal mobility and vascular tone. ${ }^{11)}$ Clinical findings of SS are related to central and peripheral receptors. Although increasing frequency of serotonergic drug use in children, pediatricians, emergency medicine and pediatric intensive care specialists have not enough knowledge and experience about SS that is a potentially life-threatening condition. Making the diagnosis of SS in children is more difficult than adults. ${ }^{12)}$ Manifestations may be falsely attributed to another cause in mild cases. On the other hand, children may not be able to communicate enough about symptoms; adolescents may be reluctant to disclose use of psychiatric drugs. There is no mandatory laboratory test or diagnostic method in diagnosis of SS. Diagnosis is mainly based on clinical history and physical findings. In our case, both clinical history and physical examination supported the diagnosis of SS. In the literature, there are three different diagnostic criteria systems for the diagnosis of
SS published by Sternbach, ${ }^{12)}$ Radomski et al. ${ }^{13)}$ and Hunter. ${ }^{14)}$ The present case meets overall diagnostic criteria defined by three researchers.

The highest risk for the development of SS is using monoaminoxidase inhibitors, which suppress serotonin metabolism, together with these drugs. ${ }^{15)}$ Herein, we report a 12-year-old girl with SS, which developed during concurrent irregular use of risperidone and clomipramine. Clomipramine, which is a member of tricyclic antidepressant group, is a noradrenalin and serotonin reuptake inhibitor. Risperidone is one of the atypical antipsychotics and the antagonist of dopamine $\mathrm{D}_{2}$, serotonin $5 \mathrm{HT}_{2 \mathrm{~A}}$ and $5 \mathrm{HT}_{2 \mathrm{C}}$ receptors. It is used in patients with behavioral disorder which is usually administrated in doses ranging from 1 to $4 \mathrm{mg} /$ day. $^{16,17)}$ The interaction of these drugs may be facilitated SS in the present case which 2D6 isoenzyme might have been overloaded producing thus a state of serotonin toxicity. More specifically, co-administration of risperidone might have enhanced the plasma concentration of clomipramine. ${ }^{17)}$ There are limited numbers of pediatric case reports in the literature.

Some of these include three cases due to sertraline use, ${ }^{3-5)}$ a case due to fluvoxamine use ${ }^{6}$ and a case due to fluoxetine use, ${ }^{7)}$ which are antidepressant agents. Grenha et $a l .^{8)}$ defined SS due to concurrent use of sertraline and risperidone in a pediatric case. However, There is no SS case report due to concurrent use of risperidone and clomipramine in literature.

In the treatment of SS, first all of serotonergic drugs must be discontinued and supportive treatment should be started. Most of the patients improve within 24 hours following discontinuation of serotonergic drug. ${ }^{11)}$ Benzodiazepine, cyproheptadine and chlorpromazine are the drugs most commonly used in the treatment of SS. Benzodiazepines are used for muscle rigidity, seizure-like movement disorders and agitations of the patients. ${ }^{18)}$ The symptoms of the present case, which was monitored in intensive care unit, regressed with fluid replacement and benzodiazepine within 24 hours as described in literature.

In conclusion, $\mathrm{SS}$ is a rare condition with high mortality. It should be diagnosed promptly and requires serious monitoring. In the present case, concurrent use of risperidone and high-dose clomipramine use caused SS. To our knowledge, this case is the first reported SS case due to concurrent clomipramine and risperidone use in literature. It is important to warn the parents of children that are using these drugs in terms of dose and symptoms. In addition, SS should be kept in mind for adolescents receiving antidepressant therapy, as they usually attempt 
suicide with their drugs. We also presented the case to emphasize that detailed anamnesis and physical examination, which could save the patient's life.

\section{REFERENCES}

1. Boyer EW, Shannon M. The serotonin syndrome. $N$ Engl $J$ Med 2005;352:1112-1120.

2. Birmes P, Coppin D, Schmitt L, Lauque D. Serotonin syndrome: a brief review. CMAJ 2003;168:1439-1442.

3. Phan H, Casavant MJ, Crockett S, Lee A, Hall MW, Nahata MC. Serotonin syndrome following a single $50 \mathrm{mg}$ dose of sertraline in a child. Clin Toxicol (Phila) 2008:46:845-849.

4. Kaminski CA, Robbins MS, Weibley RE. Sertraline intoxication in a child. Ann Emerg Med 1994;23:1371-1374.

5. Pao M, Tipnis T. Serotonin syndrome after sertraline overdose in a 5-year-old girl. Arch Pediatr Adolesc Med 1997;151:1064-1067.

6. Gill M, LoVecchio F, Selden B. Serotonin syndrome in a child after a single dose of fluvoxamine. Ann Emerg Med 1999;33:457-459.

7. Velez LI, Feng SY, Neerman MF. A dispensing error resulting in possible fluoxetine overdose and subsequent discontinuation syndrome in a child. Clin Pediatr (Phila) 2010;49:1072-1074.

8. Grenha J, Garrido A, Brito H, Oliveira MJ, Santos F. Serotonin syndrome after sertraline overdose in a child: a case report. Case Rep Pediatr 2013;2013:897902.

9. Likasitwattanakul S. Serotonin syndrome: a case report. $J$ Med Assoc Thai 2005;88:993-996.

10. Lin SH, Lee LT, Yang YK. Serotonin and mental disorders: a concise review on molecular neuroimaging evidence. Clin Psychopharmacol Neurosci 2014;12:196-202.

11. Bronstein AC, Spyker DA, Cantilena LR, Rumack BH, Dart RC. 2011 annual report of the American Association of Poison Control Centers' National Poison Data System (NPDS): 29th annual report. Clin Toxicol (Phila) 2012;50: 911-1164.

12. Sternbach H. The serotonin syndrome. Am J Psychiatry 1991;148:705-713.

13. Radomski JW, Dursun SM, Reveley MA, Kutcher SP. An exploratory approach to the serotonin syndrome: an update of clinical phenomenology and revised diagnostic criteria. Med Hypotheses 2000;55:218-224.

14. Dunkley EJ, Isbister GK, Sibbritt D, Dawson AH, Whyte IM. The Hunter serotonin toxicity criteria: simple and accurate diagnostic decision rules for serotonin toxicity. QJM 2003;96:635-642.

15. Sansone RA, Sansone LA. Tramadol: seizures, serotonin syndrome, and coadministered antidepressants. Psychiatry (Edgmont) 2009;6:17-21.

16. Kapur S, Zipursky RB, Remington G. Clinical and theoretical implications of 5-HT2 and D2 receptor occupancy of clozapine, risperidone, and olanzapine in schizophrenia. Am J Psychiatry 1999;156:286-293.

17. Nikolaou KN, Gournellis R, Michopoulos I, Dervenoulas G, Christodoulou C, Douzenis A. Neurotoxic syndrome induced by clomipramine plus risperidone in a patient with autistic spectrum disorder: serotonin or neuroleptic malignant syndrome? Ann Gen Psychiatry 2015;14:38.

18. Ables AZ, Nagubilli R. Prevention, recognition, and management of serotonin syndrome. Am Fam Physician 2010;81: 1139-1142. 